\title{
Comparison of the treatment for isopropyl alcohol wastewater from silicon solar cell industry using SBR and SBBR
}

\author{
Y. Xiao $\cdot$ H.-Y. Xu $\cdot$ H.-M. Xie $\cdot$ Z.-H. Yang $\cdot$ \\ G.-M. Zeng
}

Received: 26 August 2013/Revised: 26 March 2014/ Accepted: 3 June 2014/Published online: 17 June 2014

(C) Islamic Azad University (IAU) 2014

\begin{abstract}
In the present study, isopropyl alcohol containing wastewater generated from silicon solar cell manufacture was sequentially treated with sequencing batch biofilm reactor and sequencing batch reactor. Sequencing batch biofilm reactor could remove $90 \%$ of isopropyl alcohol from wastewater efficiently as the chemical oxygen demand lower than $1,200 \mathrm{mg} \mathrm{L}^{-1}$. However, $1,600 \mathrm{mg} \mathrm{L}^{-1}$ of chemical oxygen demand damaged the biofilm. The operation mode was changed to sequencing batch reactor on day 30 , and sequencing batch reactor showed a greater ability to remove isopropyl alcohol. When the influent chemical oxygen demand was $1,600 \mathrm{mg} \mathrm{L}^{-1}$, the reactors achieved stable removal efficiencies of $>95 \%$ for chemical oxygen demand, and the effluent chemical oxygen demand was lower than $100 \mathrm{mg} \mathrm{L}^{-1}$. Denaturing gradient gel electrophoresis analysis showed an increase in bacteria diversity as the operation mode was switched from sequencing batch biofilm reactor to sequencing batch reactor, which might increase the stability of flocs in sequencing batch reactor. Though 13 bands were sequenced from the denaturing gradient gel electrophoresis and a phylogenetic analysis was conducted based on these sequences, it is difficult to analyze the function of these predominant strains in the reactors. Two models were constructed for interpreting the structure of biofilm in sequencing batch biofilm reactor and flocs in sequencing batch reactor, respectively. Higher efficient
\end{abstract}

Y. Xiao ( $\square)$

Institute of Urban Environment, Chinese Academy of Sciences,

Xiamen 361021, China

e-mail: yxiao@iue.ac.cn

Y. Xiao - H.-Y. Xu · H.-M. Xie · Z.-H. Yang · G.-M. Zeng College of Environmental Science and Engineering, Hunan University, Changsha 410082, China transfer rate of dissolved oxygen in flocs was proposed as the main reason for the higher isopropyl alcohol removal ability in sequencing batch reactor.

Keywords Dissolved oxygen - Sequencing batch biofilm reactor - Denaturing gradient gel electrophoresis .

Industrial wastewater treatment $\cdot$ Solar energy

\section{Introduction}

The volume of isopropyl alcohol (IPA) wastewater that is yielded from the wafer cleaning process in the silicon solar cell (SSC) manufacturing industry has continuously increased due to the increase demand on solar cell to obtain clean electric power. IPA and its metabolite, acetone, act as central nervous system depressants (Burkhart and Kulig 1990). Besides, the IPA wastewater contains many other refractory and complex organic compounds, e.g., fluoride and suspended solids, which not only introduce direct or indirect contamination to environment but also are harmful to human health (Lin and Kiang 2003). However, few studies have been conducted aiming to solve this problem in the industry, and the wastewater has consequently brought the industry in China a bigger and bigger trouble since Chinese factories produced more than one-half of solar cells in the world since the year of 2010. Though methanol and ethanol are usually used as carbon source in wastewater treatment and bio-treatment of wastewater has been successfully applied as a low-cost treatment method in many other industrial applications, the use of bio-treatment for IPA wastewater has not been reported as successful as that in other industry.

Sequencing batch reactor (SBR) technology, a periodic discontinuous process with activated sludge, has been 
successfully applied for treating various types of wastewater (domestic wastewater, medium- and low-strength landfill leachate, specific organic pollutants, and various types of industrial wastewater) using diverse types of reactor configurations (Kaballo et al. 1995; Mohan et al. 2007; Lotito et al. 2013; Cui et al. 2013). The process can be considered for IPA wastewater treatment since periodic operation imposes suitable oxygen gradients on the microorganisms that overwhelm natural variations in waste strength and composition (Woolard 1997). Furthermore, the operation can maintain effective cultures within the reactor. The resulting environment therefore offers robust microbial community capable to persist and metabolize at extremely adverse and diverse conditions.

Besides, it is evident that the biofilm-configured sequencing batch systems, i.e., sequencing batch biofilm reactor (SBBR), are well suited for treating wastewater containing poorly degradable compounds (Makinen et al. 1993). In SBBR, microorganisms are immobilized on fillers as biofilm, which results in high biomass hold up and enables the process to be operated at high liquid throughputs and organic loading rates. The attached biofilm acts as buffer to reduce the concentration of toxic chemicals during process operation and thereby benefits the treatment of lowbiodegradable industrial wastewater that contains recalcitrant compounds (Bishop 1997). Compared with sludgebased systems, SBBR is generally less energy intensive and more resistant to shock loads to which wastewater treatment systems are frequently subjected (Chaudhry and Beg 1998). Besides, SBBR is particularly useful where high hydraulic loading variations occur and where slowly growing microbes with special metabolic capacities can be protected from washout (Woolard 1997). However, there are few experimental studies reported so far on the treatment of IPA wastewater by SBR or SBBR.

Since pilot experiments have showed that anaerobic treatment was unsuitable for treating IPA wastewater from SSC manufacturing industry, the object of this study was to evaluate the feasibility of using SBR or SBBR as a treatment technique for IPA wastewater. In addition, to investigate the microbial mechanism, molecular techniques, such as denaturing gradient gel electrophoresis (DGGE) and phylogenetic analysis, were employed to explore the bacterial community in the systems. The study was conducted in Changsha between November in 2009 and July in 2010.

\section{Materials and methods}

\section{Reactors operation}

Two parallel laboratory-scale reactors A and B with an effective volume of about $3 \mathrm{~L}$ (diameter: $12 \mathrm{~cm}$; height:
$30 \mathrm{~cm}$ ) were used to perform the experiment. The reactors were inoculated with $500 \mathrm{ml}$ of activated sludge (suspended solids: about $2.0 \mathrm{~g} \mathrm{~L}^{-1}$; volatile suspended solids: about $0.8 \mathrm{~g} \mathrm{~L}^{-1}$ ) from an oxidation ditch municipal wastewater treatment plant in Changsha, China. The biofilm was acclimated with IPA wastewater by continuous aeration to maintain a dissolved oxygen (DO) of $2.5-4.0 \mathrm{mg} \mathrm{L}^{-1}$ for 10 days. During the acclimation, the COD in IPA wastewater was about $300 \mathrm{mg} \mathrm{L}^{-1}$. The IPA wastewater was taken from a SSC factory in Changsha, China, and the chemical oxygen demand (COD) in IPA wastewater was $1,500-1,700 \mathrm{mg} \mathrm{L}^{-1}$.

Since some researchers have reported that the SBBR is evidently well suited for treating wastewater containing poorly degradable compounds (Makinen et al. 1993), we attempted to use SBBR to treat the IPA wastewater. Therefore, we firstly operated the reactors in SBBR mode after the 10-day acclimation. The COD in influent was increased from about 500-900, 1,200, 1,600 $\mathrm{mg} \mathrm{L}^{-1}$ step by step. Soft polypropylene fiber was used as filler. In SBR mode, soft polypropylene fiber was removed, and the biofilm was washed off from the fillers as seeding sludge. Therefore, the main difference between SBBR and SBR mode was that the sludge was in biofilm form in SBBR and in suspended flocs form in SBR. The COD in influent was increased from about 800 to $1,200,1,600 \mathrm{mg} \mathrm{L}^{-1}$ step by step. The reactors were operated in SBR mode for 50 days.

In this study, $0.14 \mathrm{~g} \mathrm{~L}^{-1} \quad \mathrm{KH}_{2} \mathrm{PO}_{4}$ and $0.05 \mathrm{~g} \mathrm{~L}^{-1}$ $\mathrm{NH}_{4} \mathrm{Cl}$ were added to the influent as the $\mathrm{P}$ and $\mathrm{N}$ source during the acclimation and operation periods, respectively. One liter of effluent was replaced with $1 \mathrm{~L}$ of influent every $8 \mathrm{~h}$, and the wastewater replacement was finished in $10 \mathrm{~min}$. Therefore, the hydraulic retention time of the reactors was $24 \mathrm{~h}$. The sludge retention time of the SBR was about 15 days. During the whole experiment, the two reactors were operated as the following repeats of a 3-h aeration phase and then a 1-h settling incubation. During the aeration, the DO in bulk solution was maintained at $2.5-4.0 \mathrm{mg} \mathrm{L}^{-1}$. The mixed liquor suspended solids and mixed liquor volatile suspended solids (excluding the biofilm) in SBBRs were about 1.0 and $0.6 \mathrm{~g} \mathrm{~L}^{-1}$, respectively. The mixed liquor suspended solids and mixed liquor volatile suspended solids in the SBRs were about 3.2 and $2.2 \mathrm{~g} \mathrm{~L}^{-1}$, respectively. The $\mathrm{pH}$ was maintained at 7 , and the temperature was $20-25^{\circ} \mathrm{C}$.

Analytical methods

Water quality parameters of $\mathrm{COD}, \mathrm{pH}$, and $\mathrm{DO}$ were measured every day. The $\mathrm{pH}$ was determined by a $\mathrm{pH}$ meter, DO was determined by a DO analyzer, and the measurements of COD were performed following standard 
methods (Eaton and Franson 2005). Removal efficiency of $\mathrm{COD}(\operatorname{Re})$ was calculated as the following equation:

$\mathrm{Re}=(1-\mathrm{Ci} / \mathrm{Ce}) \cdot 100 \%$,

where $C i$ was the concentration of COD in the added 1,000-ml influent, and $C e$ was the concentration of COD in the treated effluent. All tests have three repeats.

\section{Sampling}

Nine sludge or biofilm samples were sampled. One sample was sampled from the inoculate sludge and designated as sample 0. Samples A10, A25, A50, and A75 were sampled from reactor $A$ in the 10th, 25th, 50th, and 75th day, respectively. Samples B10, B25, B50, and B75 were sampled from reactor B in the 10th, 25th, 50th, and 75th day, respectively. The samples were immediately stored at $-20{ }^{\circ} \mathrm{C}$ for following analysis.

\section{DNA extraction and PCR amplification}

Genomic DNA was extracted from each $1 \mathrm{~g}$ of centrifuged samples (wet weight) with protease $\mathrm{K}$ and CTAB according to our previous report (Yang et al. 2007). Purified DNA was dissolved in $200 \mu \mathrm{L}$ sterilized Milli-Q water (Millipore, USA), and the concentrations of purified DNA ranged from 200 to $300 \mathrm{ng} \mu \mathrm{L}^{-1}$ by applying $5 \mu \mathrm{L}$ of DNA for agarose gel electrophoresis with a comparison with HindIII digested $\lambda$ DNA (TianGen, Beijing, China).

Primers were selected to amplify a part of $16 \mathrm{~S}$ rDNA, positioning 341-926 in Escherichia coli position. The nucleotide sequence of the forward primer, which is universal for eubacteria, contains at its $5^{\prime}$ end a 40-base GC clamp (5'-CGCCCGCCGCGCCCCGCGCCCGGCCCGC CGCCCCCGCCCG -3') (GC341F; 5'-(GC clamp)CCTACGGGAGGCAGCAG-3') (Muyzer et al. 1998; Xiao et al. 2009). A universal consensus sequence was used as the reverse primer (517R: 5'-ATTACCGCGGCTGCTGG3') (Muyzer et al. 1993; Murray et al. 1996). Each $50 \mu \mathrm{L}$ PCR mixture contained about $150 \mathrm{ng}$ of genomic DNA, 5 pmol each primer (Sangon, Shanghai, China), $25 \mu \mathrm{L}$ of $2 \times$ PCR mix (BioTek, Beijing, China), $10 \mu \mathrm{g}$ bovine serum albumin (BSA) V (Sangon), and about $22 \mu \mathrm{L}$ of sterilized Milli-Q water. PCRs were performed using a MyCycler (Bio-Rad, Hercules, USA). PCR mixtures were pre-incubated at $95{ }^{\circ} \mathrm{C}$ for $4 \mathrm{~min}$. Denaturing, annealing, and extension were carried out at 94, 55, and $72{ }^{\circ} \mathrm{C}$, respectively, and the duration was $30 \mathrm{~s}$ in all the steps. This cycle was repeated 30 times and then incubated at $72{ }^{\circ} \mathrm{C}$ for $7 \mathrm{~min}$ for the final elongation.
Denaturing gradient gel electrophoresis

The DGGE was carried out by using a DCode ${ }^{\mathrm{TM}}$ Universal Detection System instrument and gradient former model 475 (Bio-Rad) according to the manufacturer's instructions. The denaturant solution was prepared as Muyzer et al. (1998) reported, and in this study, the optimal acrylamide concentration in the gel was $8 \%$ and the optimal denaturing gradient was $35-55 \%$. Gels were run in $1 \times$ TAE buffer at $60{ }^{\circ} \mathrm{C}$ for $8 \mathrm{~h}$ at $120 \mathrm{~V}$. Gels were stained with $1 \times \mathrm{SYBR}^{\mathrm{TM}}$ Green I and visualized in UV light with the Gel Doc XR System (Bio-Rad). Bands were recognized both by the program QuantityOne V4.63 (BioRad) and manual identify; therefore, some weak bands on the DGGE pattern also were sequenced.

16S rDNA cloning, sequencing, and phylogenetic analysis

Each manually recognized band was excised from DGGE gel under UV light, and the DNA was extracted from the gel by bathing the gels in water at $4{ }^{\circ} \mathrm{C}$. The extracted DNA was amplified with primer pair GC341F/517R. The PCR products were cloned, re-DGGE affirmed, and sequenced as our previous study reported (Xiao et al. 2011a, b).

Phylogenetic identity was determined by comparing the partial 16S rDNA sequences of the clones with sequences which were found in GenBank using the BLAST (http:// blast.ncbi.nlm.nih.gov/Blast.cgi), and a phylogenetic tree was constructed using the program MEGA5 as that in our previous study (Tamura et al. 2011).

Nucleotide sequence accession numbers

The retrieved thirteen sequences of the 16S rRNA gene clones have been deposited orderly in the GenBank database under Accession No. JX872406-JX872418.

\section{Results and discussion}

\section{Reactors performance}

Figure 1 shows the average COD concentration (plus standard deviation) in influent and effluent in reactors $\mathrm{A}$ and $\mathrm{B}$. The COD removal efficiencies in both reactors were also shown in this figure. Figure 2 shows the daily removed COD of each reactor. 


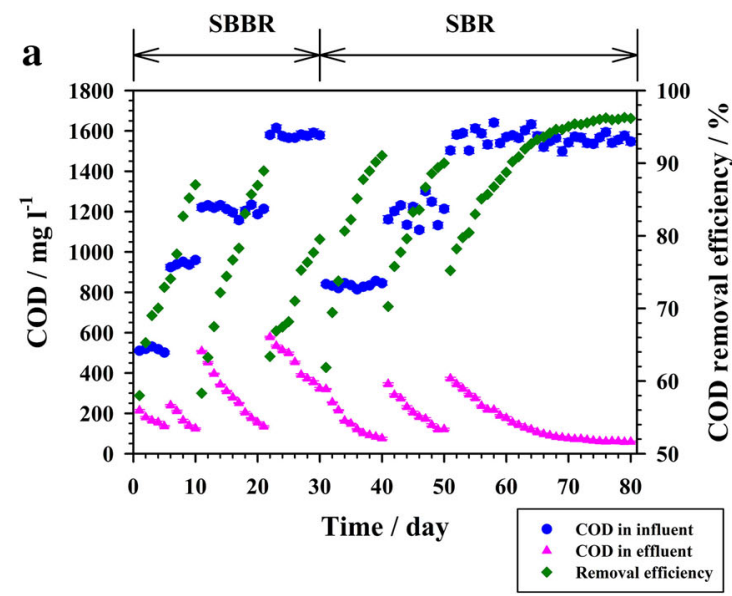

Fig. 1 COD concentrations in influent and effluent and COD removal efficiencies in reactors $\mathrm{A}(\mathbf{a})$ and $\mathrm{B}(\mathbf{b})$. The $\mathrm{COD}$ concentrations were presented as average value with standard deviation $(n=3)$. Circle

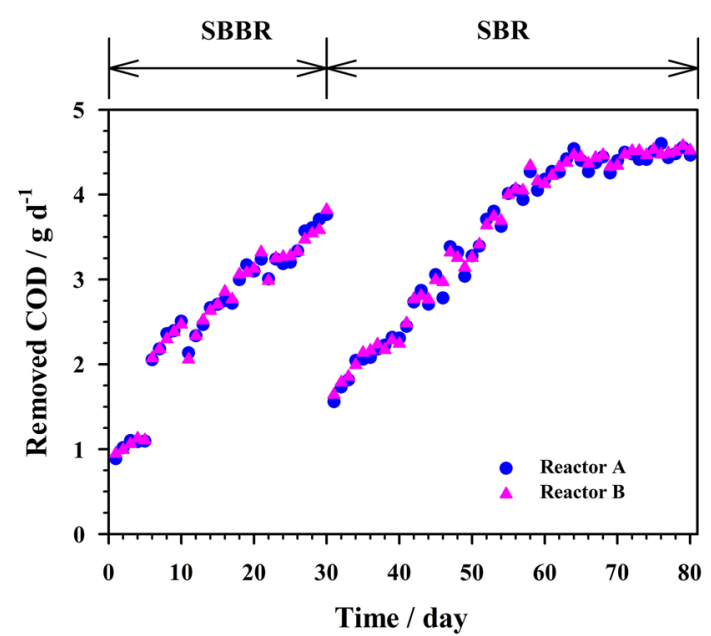

Fig. 2 Daily removed COD from reactors A and B. Circle reactor A; triangle reactor $\mathrm{B}$

At the beginning of SBBR operation (day 1), COD in influent was increased from $300 \mathrm{mg} \mathrm{L}^{-1}$ to about $500 \mathrm{mg} \mathrm{L}^{-1}$. While the effluent $\mathrm{COD}$ on the 5 th day reduced to $<150 \mathrm{mg} \mathrm{L}^{-1}$, the emission concentration standard level 2 of Integrated Wastewater Discharge Standard in China, the influent COD was increased to about $900 \mathrm{mg} \mathrm{L}^{-1}$ on day 6 and then to about $1,200 \mathrm{mg} \mathrm{L}^{-1}$ on day 11. When the influent $\mathrm{COD}$ was increased to $1,600 \mathrm{mg} \mathrm{L}^{-1}$ on day 25 , the biofilm began to fall off from the filler (mixed liquor suspended solids higher than 2,000 $\mathrm{mg} \mathrm{L}^{-1}$ ).

On the 26th day, one-half of raw IPA wastewater was reduced in influent, and $800 \mathrm{mg} \mathrm{L}^{-1}$ of glucose was added as we suspected the IPA wastewater was harmful to microbes. The biofilm continued to fall off in the following

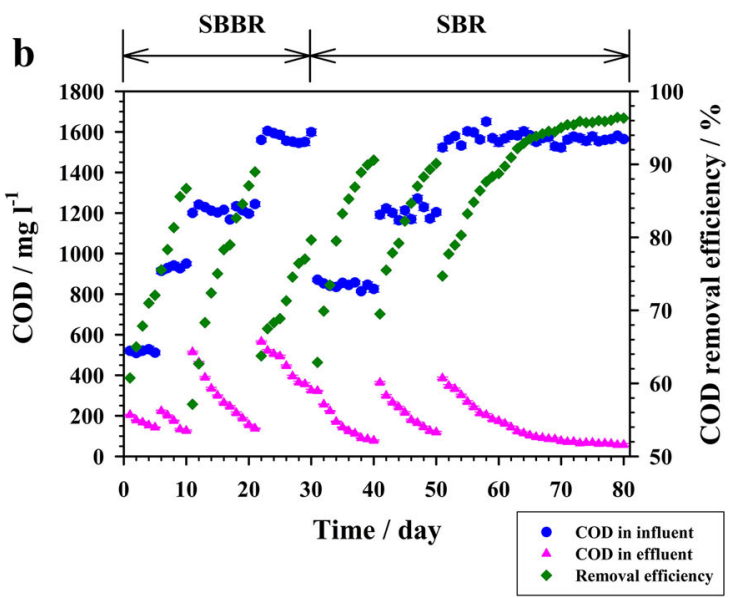

COD in influent; triangle: COD in effluent; diamond: COD removal efficiency

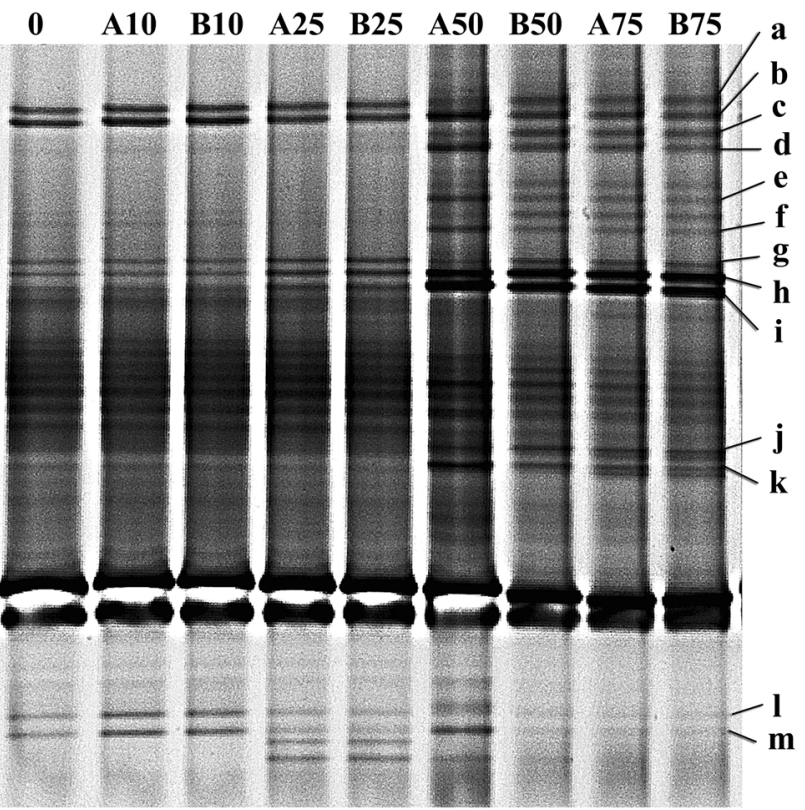

Fig. 3 DGGE analysis of the nine flocs/biofilm samples from inoculant sludge and reactors $\mathrm{A}$ and $\mathrm{B}$

5 days although the COD removal efficiencies were still growing. We suspected that high concentration of IPA might have negatively impacted the formation of some extracellular substances which was very important for the attachment of microbes on filler. Based on the inference above, the operation mode was switched from SBBR to SBR in which the flocs did not attach on fillers. Since the DGGE analysis showed that the biofilm sampled at day 25 had very similar profile with that of the activated sludge from municipal wastewater treatment plant (Fig. 3), the sludge eluted from the filler was used to start the SBR. 
At the beginning of SBR operation, no glucose was added and the influent COD was about $800 \mathrm{mg} \mathrm{L}^{-1}$. Though the daily removed COD decreased to about $1.5 \mathrm{~g}$ day $^{-1}$ on day 31 (Fig. 2), the COD removal efficiency quickly increased to $80 \%$ on day 34 and then to $90 \%$ on the 39th day (Fig. 1).

On day 41-50, the COD in influent was increased to $1,200 \mathrm{mg} \mathrm{L}^{-1}$ and the COD removal efficiencies increased stably from $70 \%$ to about $90 \%$. While the influent COD was increased from 900 to $1,200 \mathrm{mg} \mathrm{L}^{-1}$ on the 11th day (SBBR mode), both the COD removal efficiencies and the daily removed COD were lower than that on day 10 (Fig. 2). But in SBR mode, when the influent COD was increased from 800 to $1,200 \mathrm{mg} \mathrm{L}^{-1}$ on day 41 , the daily removed COD was higher than that on day 11 and day 40 (Fig. 2). This result meant that flocs in SBR had a stronger shockproof ability to high IPA, compared with biofilm in SBBR.

Then, the influent COD was increased to $1,600 \mathrm{mg} \mathrm{L}^{-1}$ on day 51, and the COD removal efficiencies in both reactors increased from about 74 to $90 \%$ in the following 10 days. The daily removed COD stabilized at about $4.5 \mathrm{~g}$ day $^{-1}$ in the last 20 days, and in the last 15 days, the effluent COD was lower than $100 \mathrm{mg} \mathrm{L}^{-1}$, the emission concentration standard level 1 Integrated Wastewater Discharge Standard in China. The results showed that the COD removal ability of flocs in SBR was obviously higher than the biofilm in SBBR. Some researchers have reported that the SBBR is evidently well suited for the treatment of wastewater containing low-biodegradable compounds including composite chemicals (Mohan et al. 2007) or chlorophenols (Makinen et al. 1993) due to the greater biomass concentration to be maintained in the reactor (Singh and Srivastava 2011). However, this study indicates that SBR is more suitable for treating high concentration IPA wastewater rather than SBBR.

DGGE analysis of the bacterial community in biofilm/ flocs

Figure 3 shows the DGGE profiles of nine samples collected from inoculum sludge and reactors A and B. Sample 0 was the inoculant sludge sampled from a municipal wastewater treatment plant. After being sequentially acclimated and operated in SBBR mode for 20 days, samples A10 and B10 showed almost the same DGGE profiles as sample 0 , which indicated that the change of carbon source and operation mode had little effect on the community of predominant bacteria. The result surprised us as a previous study showed an obvious succession of dominant bacteria in a SBBR reactor even in $4 \mathrm{~h}$ (Xiao et al. 2009). Increased IPA in influent seemed not to have much impact on the community of predominant bacteria either as the profiles of $\mathrm{A} 25$ and $\mathrm{B} 25$ were similar to that of 0 , A10, and B10.

Switching the operation mode from SBBR to SBR dramatically increased the diversity of bacteria community, and no band in lanes of SBBR disappeared from the lanes SBR (Fig. 3). Previous report demonstrates that a more diverse system possesses more resistance to perturbation than a less diverse system (Girvan et al. 2005). Therefore, the flocs in SBR might be able to tolerate higher concentration of IPA than the biofilm in SBBR. After being operated for a continued 25 days with $1,600 \mathrm{mg} \mathrm{L}^{-1} \mathrm{COD}$ in influent, the bacteria community in SBR had almost no change. The results meant that, comparing to SBBR, SBR can maintain a more diverse bacteria community and perform more stable function for removing high concentration IPA.

Thirteen bands, i.e., a to $\mathrm{m}$ in Fig. 3, were excised from DGGE gel and were successfully sequenced after being cloned into T-vector. Based on the sequences of these bands, a neighbor-joining tree (Fig. 4) was constructed by the program MEGA5 (Tamura et al. 2011). As showed in the phylogenetic tree, almost all the bands, except band $g$, showed high similarity to beta- or gamma-Proteobacteria bacteria.

Band a was $96 \%$ similar to sequences from Xenophilus sp. and Variovorax sp., and band b showed highest similarity $(97 \%)$ to sequence from Pelomonas sp. Though none of these species have been reported as an IPA degrader, both bands might be very important for IPA degradation as they showed high intensity in all DGGE lanes (Fig. 3). Band c showed low intensity in lanes from SBBR, but had high intensity in samples from SBR, which meant that SBR operation could facilitate the growth of this strain. The band showed $98 \%$ similarity to sequence from Methylibium sp. Some strains in genus Methylibium have been reported as alcohols degrader (Schäfer et al. 2011). Therefore, band c was expected to perform as a key player in degrading IPA in SBR. Band $\mathrm{f}$ showed highest similarity (95\%) to a strain of Cupriavidus basilensis, which was reported as a degrader for many recalcitrant contaminants (Fischer et al. 2010; Koopman et al. 2010; Wierckx et al. 2010). The band was only detected in samples from SBR, indicating that SBR might facilitate its ability to degrading IPA. Bands h and i, showing $100 \%$ similarity to E. coli and $99 \%$ similarity to Azonexus sp., respectively, both were detected in all samples and had higher intensity in samples from SBR than that from SBBR, which meant that SBR was more suitable for their growth in IPA wastewater. $E$. coli is a widespread bacterium in natural environment, but the result surprised us since there was no report on the degradation with the bacterium.

Several bands of $\mathrm{d}, \mathrm{e}, \mathrm{g}, \mathrm{j}, \mathrm{k}, \mathrm{l}$, and $\mathrm{m}$ could not be assigned to specific species. Thus, it is difficult to discuss 


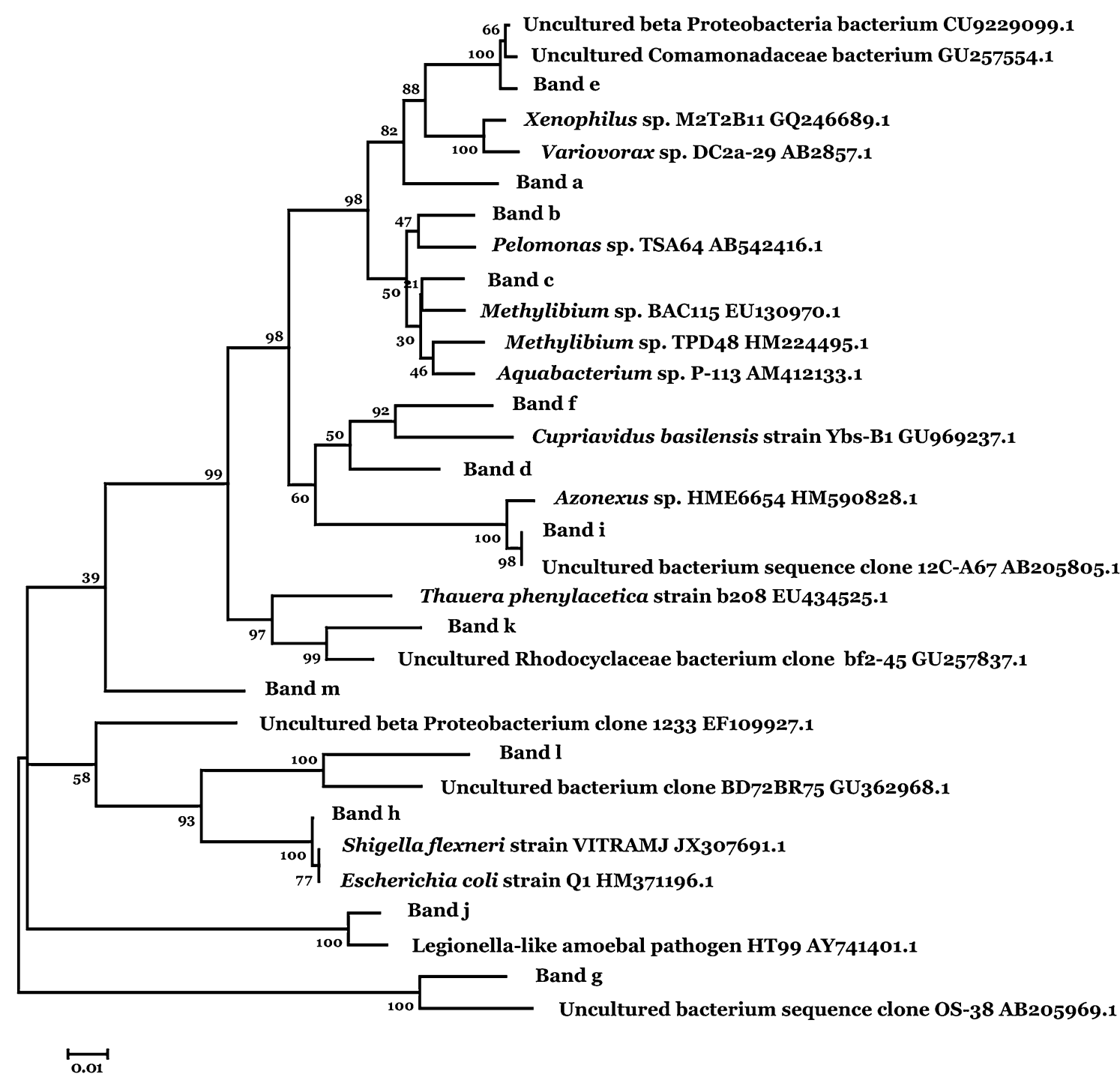

Fig. 4 Neighbor-joining tree showing the phylogenetic relationship of clones sourced from DGGE bands aligned with reference sequences from the domain Bacteria based on 16S rRNA gene

how they performed the function of degrading IPA in SBBR or SBR. Though, we could expect bands d, e, j, and $\mathrm{k}$ to play important roles in degrading IPA in SBR since they were detected with high intensity in samples from SBR.

Potential effects of SBBR and SBR on biofilm/flocs

The operation results obviously showed that flocs in SBR could tolerate and remove higher concentration of IPA better than the biofilm in SBBR. The DGGE analysis showed an increase of bacterial diversity in SBR. Phylogenetic analysis was also used to explore the potential functions of the predominant bacteria in degrading IPA. Though, it is still uncertain how the bacterial community sequences. Numbers at nodes indicate percentages of 1,000 bootstrap replications. Clones studied herein are presented as Band a to $\mathrm{m}$

was affected by the operation mode change from SBBR to SBR. In aerobic condition, IPA might be degraded to $\mathrm{CO}_{2}$ by microorganisms. Therefore, DO and substrates transportation can influence the activity of biofilm/flocs, and we proposed two modes for substrates transportation and DO within biofilm in SBBR and flocs in SBR, respectively (Fig. 5).

The main difference between SBBR and SBR was the sludge structure which was in biofilm form in SBBR and suspended form in SBR, respectively. Different structure significantly affects the DO and substrates transfer rates inside the sludge aggregation. The thickness and compactness will also have impact on the DO/substrates transfer in biofilm/flocs. However, the thickness of biofilm (about $2 \mathrm{~mm}$ ) is similar to the semi-diameter of flocs, and 
Fig. 5 Schematic of DO and mass transfer inside biofilm in sequencing batch biofilm reactor (a) and flocs in sequencing batch reactor (b). The bold arrows present the direction of DO and mass transfer
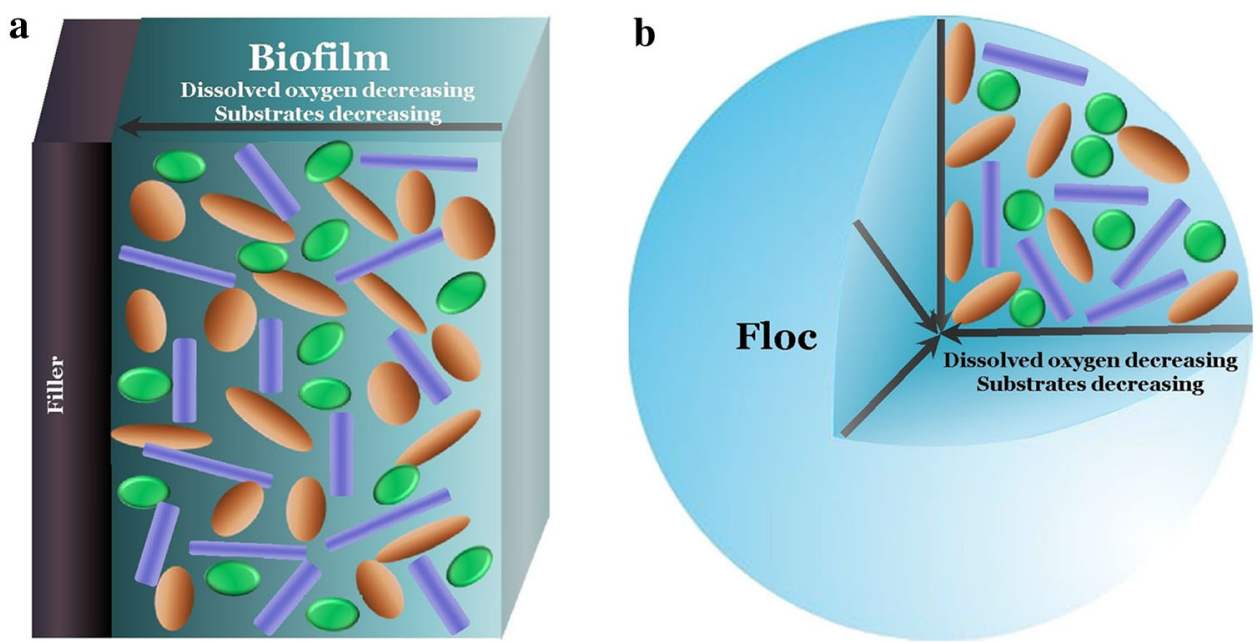

both the biofilm and flocs showed very similar compactness under a microscopy. Therefore, the sludge structure was the main factor influencing the DO and substrates transfer rates inside the sludge aggregation. The thickness of biofilm is much less than the length of fillers. So, the DO and substrates, affecting the growth of innermost microorganisms in biofilm, were mainly from the same plane with the bacteria (Fig. 5a). The flocs can be supposed to a sphericallike structure, and bacteria, even in the core, can acquire DO and substrates from any direction (Fig. 5b).

In wastewater biological treatment systems, DO is usually the major factor affecting the performance of microbial community. Studies have reported that DO will dramatically decrease as the depth of aggregation increases (Bishop et al. 1995; de la Rosa and Yu 2005). When the IPA concentration was low, such as $1,200 \mathrm{ml} \mathrm{L}^{-1}$ in this study, the DO might be available for bacteria in the innermost biofilm. As the COD was continuously increasing, DO consumed by the bacteria in surface biofilm increased and bacteria in the innermost biofilm could hardly gain enough DO. Thus, many aerobic bacteria in inner biofilm were going to die, and the biofilm became easily detached which might decrease the quality of effluent. Moreover, we had to increase the aeration rate to maintain a reasonable DO in the reactors, which further damaged the structure of biofilm. In flocs, DO could be efficiently transferred to the inner of flocs and bacteria would not die for lacking DO and substrates. The increase of COD would not induce disintegration of flocs. Moreover, IPA wastewater from SSC industry usually contain a mass of $\mathrm{Na}_{2} \mathrm{SiO}_{3}$, which will combine with extracellular polymers and improve the flocs settling. All in all, flocs in SBR was more conducive to the DO and substrates transfer than biofilm in SBBR, and therefore, SBR was more suitable for high IPA wastewater treatment.

\section{Conclusion}

IPA wastewater from SSC industry was sequentially treated with SBBR and SBR. SBR showed greater ability to remove IPA. When the influent contained $1,600 \mathrm{mg} \mathrm{L}^{-1}$ of COD, SBR achieved stable COD removal efficiencies of $>95 \%$. Switching the operation mode from SBBR to SBR could increase the stability of flocs in SBR. Two structure models were constructed for biofilm in SBBR and flocs in SBR, respectively. High efficient DO transfer in flocs was proposed as the main reason for its stronger tolerance on high concentration of IPA and higher IPA removal efficiencies.

Acknowledgments We thank Yue Zheng for his help in drawing Fig. 5b. This study was partially supported by Hunan Qingzhiyuan EnTech Co. Ltd. and National Natural Science Foundation of China (Grant 30970105).

\section{References}

Bishop PL (1997) Biofilm structure and kinetics. Water Sci Technol 36:287-294

Bishop PL, Zhang TC, Fu YC (1995) Effects of biofilm structure, microbial distributions and mass transport on biodegradation processes. Water Sci Technol 31:143-152

Burkhart K, Kulig K (1990) The other alcohols. Methanol, ethylene glycol, and isopropanol. Emerg Med Clin North Am 8:913-928

Chaudhry MAS, Beg SA (1998) A review on the mathematical modeling of biofilm processes: advances in fundamentals of biofilm modeling. Chem Eng Technol 21:701-710

Cui Y, Ding J, Ji S, Peng Y (2014) Start-up of halophilic nitrogen removal via nitrite from hypersaline wastewater by estuarine sediments in sequencing batch reactor. Int J Environ Sci Technol 11:281-292

de la Rosa C, Yu T (2005) Three-dimensional mapping of oxygen distribution in wastewater biofilms using an automation system and microelectrodes. Environ Sci Technol 39:5196-5202 
Eaton AD, Franson MAH (2005) Standard methods for the examination of water \& wastewater. American Public Health Association, Washington

Fischer J, Kappelmeyer U, Kastner M, Schauer F, Heipieper HJ (2010) The degradation of bisphenol a by the newly isolated bacterium Cupriavidus basilensis jf1 can be enhanced by biostimulation with phenol. Int Biodeter Biodegrad 64:324-330

Girvan MS, Campbell CD, Killham K, Prosser JI, Glover LA (2005) Bacterial diversity promotes community stability and functional resilience after perturbation. Environ Microbiol 7:301-313

Kaballo HP, Zhao YG, Wilderer PA (1995) Elimination of p-chlorophenol in biofilm reactors-a comparative-study of continuous-flow and sequenced batch operation. Water Sci Technol 31:51-60

Koopman F, Wierckx N, De Winde JH, Ruijssenaars HJ (2010) Identification and characterization of the furfural and 5-(hydroxymethyl) furfural degradation pathways of Cupriavidus basilensis hmf14. Proc Natl Acad Sci 107:4919-4924

Lin SH, Kiang CD (2003) Combined physical, chemical and biological treatments of wastewater containing organics from a semiconductor plant. J Hazard Mater 97:159-171

Lotito AM, De Sanctis M, Rossetti S, Lopez A, Di Iaconi C (2014) On-site treatment of textile yarn dyeing effluents using an integrated biological-chemical oxidation process. Int J Environ Sci Technol 11:623-632

Makinen PM, Theno TJ, Ferguson JF, Ongerth JE, Puhakka JA (1993) Chlorophenol toxicity removal and monitoring in aerobic treatment-recovery from process upsets. Environ Sci Technol 27:1434-1439

Mohan SV, Rao NC, Sarma PN (2007) Low-biodegradable composite chemical wastewater treatment by biofilm configured sequencing batch reactor (SBBR). J Hazard Mater 144:108-117

Murray AE, Hollibaugh JT, Orrego C (1996) Phylogenetic compositions of bacterioplankton from two California estuaries compared by denaturing gradient gel electrophoresis of $16 \mathrm{~s}$ rDNA fragments. Appl Environ Microb 62:2676-2680

Muyzer G, De Waal EC, Uitterlinden AG (1993) Profiling of complex microbial populations by denaturing gradient gel electrophoresis analysis of polymerase chain reaction-amplified genes coding for 16s rrna. Appl Environ Microb 59:695-700

Muyzer G, Brinkhoff T, Nübel U, Santegoeds C, Schäfer H, Wawer C (1998) Denaturing gradient gel electrophoresis (DGGE) in microbial ecology. Mol Microb Ecol Man 3.4.4: 1-27

Schäfer F, Muzica L, Schuster J et al (2011) Formation of alkenes via degradation of tert-alkyl ethers and alcohols by Aquincola tertiaricarbonis 1108 and Methylibium spp. Appl Environ Microb 77:5981-5987

Singh M, Srivastava R (2011) Sequencing batch reactor technology for biological wastewater treatment: a review. Asia-Pac J Chem Eng 6:3-13

Tamura K, Peterson D, Peterson N, Stecher G, Nei M, Kumar S (2011) Mega5: molecular evolutionary genetics analysis using maximum likelihood, evolutionary distance, and maximum parsimony methods. Mol Biol Evol 28:2731-2739

Wierckx N, Koopman F, Bandounas L, De Winde JH, Ruijssenaars HJ (2010) Isolation and characterization of Cupriavidus basilensis hmf14 for biological removal of inhibitors from lignocellulosic hydrolysate. Microb Biotechnol 3:336-343

Woolard CR (1997) The advantages of periodically operated biofilm reactors for the treatment of highly variable wastewater. Water Sci Technol 35:199-206

Xiao Y, Zeng GM, Yang ZH et al (2009) Coexistence of nitrifiers, denitrifiers and anammox bacteria in a sequencing batch biofilm reactor as revealed by PCR-DGGE. J Appl Microbiol 106:496-505

Xiao Y, Zeng GM, Yang ZH et al (2011a) Effects of continuous thermophilic composting (CTC) on bacterial community in the active composting process. Microbial Ecol 62:1-10

Xiao Y, Zeng GM, Yang ZH et al (2011b) Changes in the actinomycetal communities during continuous thermophilic composting as revealed by denaturing gradient gel electrophoresis and quantitative PCR. Bioresour Technol 102:1383-1388

Yang ZH, Xiao Y, Zeng GM, Xu ZY, Liu YS (2007) Comparison of methods for total community DNA extraction and purification from compost. Appl Microbiol Biot 74:918-925 